\title{
The Outer Membrane Protein TolC from Sinorhizobium meliloti Affects Protein Secretion, Polysaccharide Biosynthesis, Antimicrobial Resistance, and Symbiosis
}

\author{
Ana M. Cosme, ${ }^{1}$ Anke Becker, ${ }^{2,3}$ Mário R. Santos, ${ }^{1}$ Larissa A. Sharypova, ${ }^{2}$ Pedro M. Santos, ${ }^{1}$ and \\ Leonilde M. Moreira ${ }^{1}$ \\ ${ }^{1}$ IBB-Institute for Biotechnology and Bioengineering, Centre for Biological and Chemical Engineering, Instituto Superior \\ Técnico, Av. Rovisco Pais, 1049-001 Lisboa, Portugal; ${ }^{2}$ Institute for Genome Research and Systems Biology, Center \\ for Biotechnology, Bielefeld University, P.O. 33501, Bielefeld, Germany; ${ }^{3}$ Institute of Biology III, University of Freiburg, \\ Schänzlestr. 1, 79104 Freiburg, Germany
}

Submitted 14 December 2007. Accepted 26 March 2008.

\begin{abstract}
Sinorhizobium meliloti is capable of establishing a symbiotic nitrogen fixation relationship with Medicago sativa. During this process, it must cope with diverse environments and has evolved different types of transport systems that help its propagation in the plant roots. TolC protein family members are the outer-membrane components of several transport systems involved in the export of diverse molecules, playing an important role in bacterial survival. In this work, we have characterized the protein TolC from S. meliloti 2011. An insertional mutation in the tolC gene strongly affected the resistance phenotype to antimicrobial agents and induced higher susceptibility to osmotic and oxidative stresses. Immunodetection experiments and comparison of the extracellular proteins present in the supernatant of the wild-type versus tolC mutant strains showed that the calcium-binding protein ExpE1, the endoglycanase ExsH, and the product of open reading frame SMc04171, a putative hemolysin-type calcium-binding protein, are secreted by a TolC-dependent secretion system. In the absence of TolC, neither succinoglycan nor galactoglucan were detected in the culture supernatant. Moreover, $S$. meliloti tolC mutant induced a reduced number of nonfixing nitrogen nodules in $M$. sativa roots. Taken together, our results confirm the importance of TolC in protein secretion, exopolysaccharide biosynthesis, antimicrobials resistance, and symbiosis.
\end{abstract}

Additional keywords: EPS I, EPS II, type I secretion.

TolC homologs are present in the outer membrane of gramnegative bacteria and, together with other components of efflux or transport pumps, are involved in the export of chemically diverse molecules (Sharff et al. 2001). The best-characterized TolC protein is from Escherichia coli and its crystal structure has been solved to high resolution (Koronakis et al. 2000). The protein exists functionally as a trimer forming a $\beta$-barrel that is embedded in the outer membrane. The remainder of the tube protrudes into the periplasmic space and is composed of $\alpha$ helices (Andersen et al. 2002; Koronakis et al. 2000). By inter-

Corresponding author: L. M. Moreira; Telephone: +(351)-218419031; Fax: +(351)-218419199; E-mail: 1moreira@ist.utl.pt acting with a wide range of different membrane translocases such as the ATP-binding cassette-membrane fusion protein (ABC-MFP), the resistance nodulation division (RND-MFP), or the major facilitator superfamily (MFS-MFP), TolC family members play a critical role in conferring virulence and drug resistance to bacteria. For example, TolC is involved in the export of proteins and other molecules toxic to its host, such as metalloproteases in Erwinia chrysanthemi (Letoffe et al. 1990); $\alpha$-hemolysin, colicin V, the peptide antibiotic Microcin $\mathrm{J} 25$, and the siderophore Enterobactin in Escherichia coli (Bleuel et al. 2005; Delgado et al. 1999; Goebel and Hedgpeth 1982); and a lipase from Serratia marcescens (Akatsuka et al. 1995), among others. The role of TolC in other pathogenic bacteria, such as Brucella suis (Posadas et al. 2007) and Vibrio cholerae (Bina and Mekalanos 2001), is also well known, with the tolC-deficient strains displaying an attenuation of infection or colonization in animal models, respectively. TolC homologs also have a critical role in the export of compounds that are toxic to the bacterium, such as antimicrobials (Bina and Mekalanos 2001; Nikaido 2000; Posadas et al. 2007). Furthermore, the TolC homologs from Erwinia chrysanthemi and $X y$ lella fastidiosa were implicated in resistance to antimicrobial plant chemicals such as Berberine, Genistein, and Rhein (Barabote et al. 2003; Reddy et al. 2007). Additionally, both $E$. chrysanthemi and $X$. fastidiosa mutants were unable to grow in planta and their ability to cause plant disease was severely compromised (Barabote et al. 2003; Reddy et al. 2007).

Although the role of TolC in many pathogenic bacteria has been established, the role of a TolC homolog in a plant-symbiotic bacterium such as Rhizobia was not determined. NodT, a TolC homolog from Rhizobium leguminosarum, together with the membrane transport proteins NodI and NodJ, were proposed to be involved in the secretion of nodulation factors but no experimental evidence was obtained (Rivilla et al. 1995). A wellknown protein from $R$. leguminosarum with a role in signaling during nodulation, NodO, is secreted by the type I secretion system PrsD/PrsE (Finnie et al. 1997). Despite the observation that NodO can be secreted by Escherichia coli containing either HlyBD/TolC (required for $\alpha$-hemolysin secretion) or PrtDEF (required for protease secretion in Erwinia chrysanthemi), no TolC-like protein from $R$. leguminosarum was identified as being responsible for NodO secretion (Scheu et al. 1992). Sequence analysis of the Sinorhizobium meliloti genome predicts 
at least 18 proteins putatively secreted by type I secretion systems, but the outer membrane component of these transporters is largely unknown (Delepelaire 2004). Among these S. melilotisecreted proteins, two of them, ExsH and ExpE1, were characterized previously (Moreira et al. 2000; York and Walker 1997, 1998). The exsH gene is situated in the vicinity of the exo genes, dedicated to the biosynthesis of the symbiotically active exopolysaccharide succinoglycan (EPS I), and codes for an endo1,3-1,4- $\beta$-glycanase (York and Walker 1997). This protein is secreted by the type I secretion system composed of PrsD and PrsE and depolymerizes nascent high molecular weight (HMW) succinoglycan to yield low molecular weight (LMW) succinoglycan (York and Walker 1997, 1998). ExsH is not required for the biosynthesis of succinoglycan because the exs $H$ mutant produces wild-type exopolysaccharide levels with increased amount of the HMW fraction at the expense of the LMW fraction (York and Walker 1997). Although LMW-EPS I has been implicated in $S$. meliloti invasion of alfalfa root nodules and the cultures of the exs $H$ mutant or its transport system accumulate little LMWEPS I, neither the PrsD/PrsE secretion system nor the ExsH succinoglycan depolymerase are required for the establishment of symbiosis between S. meliloti and alfalfa (York and Walker 1997). The other $S$. meliloti extracellular protein already characterized is ExpE1. The gene encoding ExpE1 is located within the $\exp$ gene cluster dedicated to the biosynthesis of the second exopolysaccharide, galactoglucan (EPS II) (Becker et al. 1997). ExpE1 is a $\mathrm{Ca}^{2+}$-binding protein secreted by the type I secretion system ExpD1/ExpD2 and a mutation in each of these three genes abolished extracellular EPS II recovery, implying that they are required for biosynthesis or secretion of galactoglucan (Moreira et al. 2000). Mutations in ExpE1 or its transport system had no effect on the symbiosis between $S$. meliloti and alfalfa because, in the Sm2011 background, EPS I is produced and plays a major role in the establishment of an effective symbiosis (Moreira et al. 2000).

In this report, we present the characterization of the $S$. meliloti TolC homolog and demonstrate its importance in protein secretion and, in particular, ExpE1 and ExsH secretion, EPS I and EPS II biosynthesis, resistance to antimicrobial plant chemicals, and involvement in the nitrogen fixation symbiosis between S. meliloti and alfalfa.

\section{RESULTS}

Sequence analysis of the $S$. meliloti tolC gene region.

The tolC gene homolog from S. meliloti 1021 is located in the chromosome between position 1629672 and 1631039 (open reading frame [ORF] SMc02082) and is predicted to code for a 456-amino-acid protein. A putative promoter sequence with -10 (ACGTATTAT) and -35 (CTGCAA) regions lies 229 nucleotides upstream of the start codon. The deduced amino acid sequence of the $S$. meliloti tolC gene suggests that the protein has a signal peptide at its amino terminus. The Target P 1.1 software (Nielsen et al. 1997) identified a peptidase cleavage site between ala27 and glu28, which is in agreement with other TolC proteins already characterized (Barabote et al. 2003; Hackett and Reeves 1983). Sequence homology between
S. meliloti TolC and proteins from other bacteria revealed $58 \%$ amino acid identity with a TolC-like protein from Hoeflea phototrophica; between 49 and 50\% with proteins from Ochrobactrum anthropi, a Aurantimonas sp., and several species of the genus Brucella; and between 42 and $47 \%$ with proteins from the genera Mesorhizobium, Fulvimarina, Methylobacterium, Azorhizobium, Bradyrhizobium, and Rhodopseudomonas. The percentage of identity between $S$. meliloti TolC and characterized proteins from the genera Escherichia, Erwinia, Vibrio, and Serratia varied between 24 and $26 \%$.

Within the $S$. meliloti genome, the proteins with stronger similarity to TolC are encoded by ORF SMc02281 and SMa1037 but they display less than $20 \%$ homology at the amino acid level with TolC, have only one outer membrane efflux protein (OEP) pfam domain instead of two like TolC, and have a predicted lipid attachment site.

\section{Construction and characterization of the $S$. meliloti tolC mutation.}

In order to construct a Sm2011 mutant, an internal fragment of the tolC coding region was inserted into the suicide vector pK 19 mob $2 \Omega H M B$ and insertionally inactivated the wild-type gene. Confirmation of the chromosomal gene disruption was made by Southern hybridization and polymerase chain reaction (PCR) analysis. The strain obtained was designated SmLM030. The growth curve of strain SmLM030 in TY medium (Beringer 1974) was compared with that of the wild-type Sm2011 and both strains showed identical specific growth rates (data not shown).

To characterize the possible phenotype of the SmLM030 tolC mutant, we examined its sensitivity to a variety of chemicals previously demonstrated to be substrates for the Escherichia coli multidrug resistance (MDR) efflux systems such as novobiocin, deoxycholate, and sodium dodecyl sulfate (SDS). The results are presented in Table 1 and showed that SmLM030 is more sensitive to these compounds when compared with strain SmLM051 (wild-type strain with a neomycin resistant marker). The tolC mutant complemented in trans with plasmid pLM472 expressing the tolC gene under its own promoter rescued the bacterium to drug resistance (Table 1). These results suggest that the protein TolC from $S$. meliloti has a role in resistance to antimicrobial agents, which is in agreement with the behavior of TolC from E. coli, Erwinia chrysanthemi, and B. suis, among others (Barabote et al. 2003; Fralick 1996).

In order to test the sensitivity of SmLM030 to oxidative stress conditions, $\mathrm{H}_{2} \mathrm{O}_{2}$ and methyl violagen (paraquat) were tested. When SmLM030 was challenged with either 10, 50, or $100 \mathrm{mM} \mathrm{H}_{2} \mathrm{O}_{2}$, it exhibited a larger zone of inhibition than the parental strain, and this defect could be complemented by plasmid pLM47-2 (Table 1). Under all $\mathrm{H}_{2} \mathrm{O}_{2}$ concentrations tested, SmLM030 was approximately $25 \%$ more susceptible than the wild-type strain. When incubated in the presence of paraquat, which generates superoxide intracellularly, no difference was detected from the wild-type strain, even when a solution of $1 \mathrm{M}$ was used (data not shown).

To evaluate the behavior of SmLM030 in the presence of osmotic stress, the cells were incubated with increasing con-

Table 1. Sensitivity of Sinorhizobium meliloti tolC mutant to antimicrobial agents

\begin{tabular}{|c|c|c|c|c|c|}
\hline \multirow[b]{2}{*}{ Strains } & \multirow[b]{2}{*}{ Genotype } & \multicolumn{4}{|c|}{ Diameter $(\mathrm{mm})$ of the zone of inhibition in the presence of ${ }^{\mathrm{a}}$} \\
\hline & & NOV & SDS & DOC & $\mathrm{H}_{2} \mathrm{O}_{2}{ }^{\mathrm{b}}$ \\
\hline SmLM051/pPHU231 & Y21420::pLM51-4 & $47 \pm 1$ & $13 \pm 1$ & $10 \pm 1$ & $8 \pm 0$ \\
\hline SmLM030/pPHU231 & tolC::pLS378 & $77 \pm 3$ & $63 \pm 3$ & $52 \pm 1$ & $10 \pm 0$ \\
\hline SmLM030/pLM47-2 & tolC::pLS378/tolC & $45 \pm 1$ & $21 \pm 1$ & $6 \pm 1$ & $6 \pm 0$ \\
\hline
\end{tabular}

${ }^{a}$ Results represent the average from three independent experiments. NOV = novobiocin, SDS = sodium dodecyl sulfate, and DOC $=$ deoxycholate.

${ }^{b}$ Values obtained in the presence of $10 \mathrm{mM} \mathrm{H}_{2} \mathrm{O}_{2}$. 
centrations of $\mathrm{NaCl}$. When compared with the wild-type strain, the minimal inhibitory concentration (MIC) of SmLM030 was twofold lower $(0.375 \mathrm{M} \mathrm{NaCl}$ for SmLM030/pPHU231 against $0.75 \mathrm{M}$ for SmLM051/pPHU231) and this defect could be complemented by plasmid pLM47-2 expressing the tolC gene (data not shown).

\section{The $S$. meliloti tolC mutant is sensitive to antimicrobial plant chemicals.}

The $S$. meliloti tolC mutant SmLM030 seems to be more sensitive to several stress agents; therefore, we evaluated its behavior in the presence of plant-derived molecules with known antimicrobial properties. For that, we used the MIC assay and three antimicrobials to compare the sensitivities of the wild-type with the tolC mutant strain in GMS medium (York and Walker 1997) (Table 2). In general, the tolC mutant showed increased sensitivity to the plant-derived chemicals in the tested medium. When compared with the wild-type strain, the MIC assays for the tolC mutant strain grown in the presence of the alkaloid Berberine, the phenolic compound p-Coumaric acid, and the isoflavonoid Genistein were found to be at least 125-fold, twofold, and eightfold lower, respectively (Table 2). The tolC mutant complemented in trans with plasmid pLM47-2 expressing the tolC gene rescued the bacterium to drug resistance (Table 2).

\section{TolC is involved in the secretion of ExsH, ExpE1, and} a novel hemolysin-type calcium-binding protein.

The TolC-like proteins are the outer membrane component of type I secretion systems and the two $S$. meliloti proteins

Table 2. Minimal inhibitory concentration assays of plant-derived chemicals in GMS medium (York and Walker 1997)

\begin{tabular}{lccc}
\hline & \multicolumn{3}{c}{${\text { MIC }(\mu \mathrm{g} / \mathbf{m l}) \text { of }^{\mathbf{a}}}$} \\
\cline { 2 - 4 } Chemical & $\begin{array}{c}\text { SmLM051/ } \\
\text { pPHU231 }\end{array}$ & $\begin{array}{c}\text { SmLM030/ } \\
\text { pPHU231 }\end{array}$ & $\begin{array}{c}\text { SmLM030/ } \\
\text { pLM47-2 }\end{array}$ \\
\hline Berberine & 1,000 & $<8$ & 1,000 \\
$p$-Coumaric acid & 500 & 250 & $>1,000$ \\
Genistein & 63 & $<8$ & 63 \\
\hline
\end{tabular}

${ }^{a}$ Results represent the average from three independent experiments.
ExsH and ExpE1 are secreted by type I secretion systems; therefore, we investigated whether they are secreted via TolC. For easier recovery of the protein extracts from GMS growth media, a mutation in the exoY gene blocking EPS I production (Keller et al. 1995) was introduced in all strains under study. Strains RmAR9007, SmAC07-1, SmLM031, and SmLM031/pLM47-2 were grown in GMS medium and the presence of ExsH in the cells and supernatant was assessed using an antibody against ExsH. ExsH protein was detected in the cells of RmAR9007, SmLM031, and SmLM031/pLM47-2 but absent from the exsH mutant cells (SmAC07-1) (Fig. 1A, lanes 1 to 4 ). The analysis of the extracellular proteins revealed the absence of ExsH from the supernatant of the tolC mutant strain SmLM031 (Fig. 1A, lane 6), confirming the need of a functional TolC protein for secretion of ExsH. In trans complementation of the tolC gene mutation restored the presence of ExsH in the culture supernatant (Fig. 1A, lane 8).

To investigate whether the TolC protein together with the ExpD1/ExpD2 type I secretion system is involved in the secretion of ExpE1, a mutation in the mucR gene encoding a transcriptional regulator was introduced into SmLM030 strain, in addition to the exoY mutation referred above. MucR is a known repressor of exp gene expression, which is the cluster of genes directing biosynthesis of EPS II (Becker et al. 1997). Both exoY and mucR mutations were transduced into $S$. meliloti SmLM030 and the resulting strain was designated SmLM032. The strains under study were grown in phosphate-limiting conditions and assayed for the presence of ExpE1 in cells and supernatant using the anti-ExpE1 $1_{\mathrm{C} \text {-term }}$ antibody. The result indicated that ExpE1 is present in the cell extract of the tolC mutant strain but absent from the supernatant (Fig. 1B, lanes 2 and 6). As a positive control, strain SmLM8311 was used and it was possible to observe ExpE1 in both the cell extract and supernatant (Fig. 1B, lanes 1 and 5). Although SmLM8311 has a third mutation in the expA3 gene in order to knock out EPS II biosynthesis and facilitate extracellular protein recovery, no difference was seen concerning ExpE1 secretion if strain RmAR9007 TD101 (exoY mucR) was used (data not shown). The negative control was the expE1 deletion mutant SmLM9836 (Fig. 1B, lanes 4 and 8). To restore the ability of SmLM032 to express tolC, the replicative plasmid pLM47-2 carrying the tolC gene was transferred to SmLM032
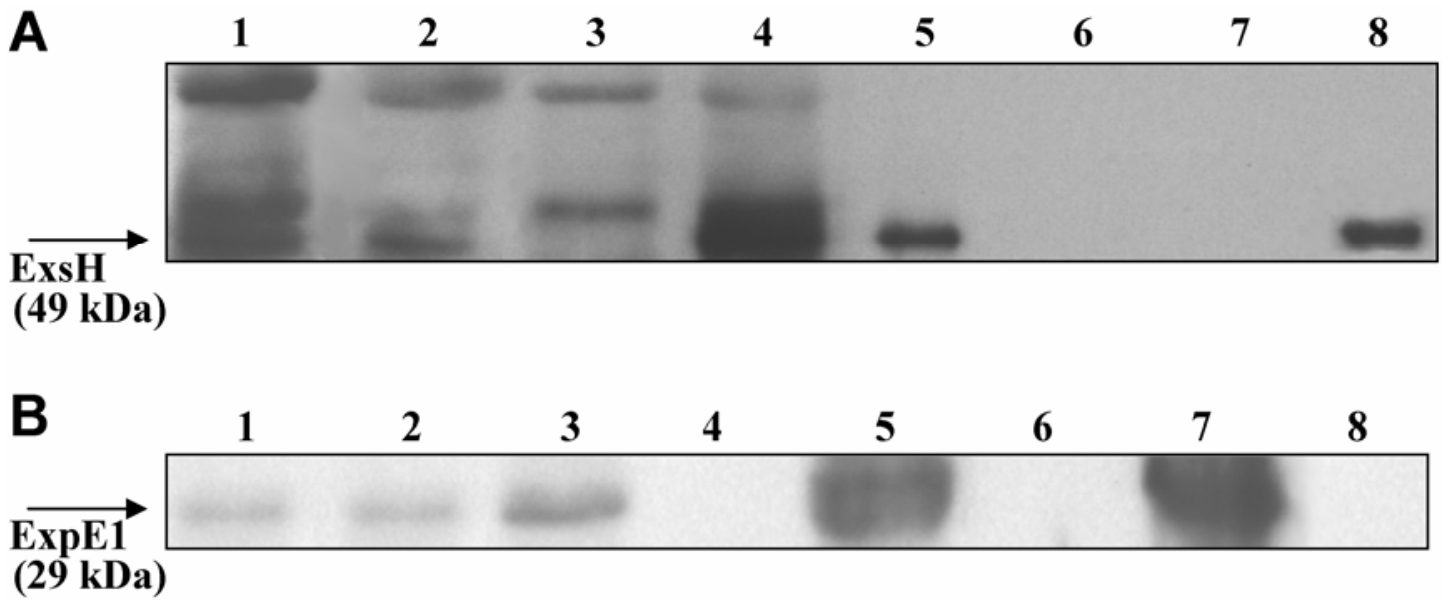

Fig. 1. TolC is involved in the secretion of ExsH and ExpE1 proteins. A, Western blot analysis of ExsH in total-cell proteins (lanes 1 through 4 ) and supernatants (lanes 5 through 8) of Sinorhizobium meliloti strains using anti-ExsH polyclonal antibody. RmAR9007 (exoY) (lanes 1 and 5), SmLM031 (tolC::pLS378 exoY) (lanes 2 and 6), SmAC07-1 (exoY exsH) (lanes 3 and 7), and SmLM031 complemented in trans with plasmid pLM47-2 expressing the tolC gene (lanes 4 and 8). Lanes contain either the cells (without supernatant) from the equivalent of $15 \mu 1$ of culture (optical density at 600 nm [OD 600$]$ between 1.5 and 2.0) or $2.5 \mu \mathrm{g}$ of cell-free supernatants. B, Western blot analysis of ExpE1 in total-cell proteins (lanes 1 through 4 ) and supernatants (lanes 5 through 8) of $S$. meliloti strains using anti-ExpE1 ${ }_{\text {C-term }}$ polyclonal antibody. SmLM8311 (expA3 exoY mucR) (lanes 1 and 5), SmLM032 (tolC::pLS378 exoY mucR) (lanes 2 and 6), SmLM032 harboring plasmid pLM47-2 (lanes 3 and 7), and SmLM9836 ( $\Delta \operatorname{expE1~exoY~mucR)~(lanes~} 4$ and 8). Lanes contain either the cells (without supernatant) from the equivalent of $15 \mu \mathrm{l}$ of culture $\left(\mathrm{OD}_{600}=1.5\right.$ to 2.0$)$ or $2.5 \mu \mathrm{g}$ of cell-free concentrated supernatants. ExsH and ExpE1 are indicated by an arrow. 
and ExpE1 was detected in both the cell extract and supernatant (Fig. 1B, lanes 3 and 7). This result implies that, in addition to ExpD1 and ExpD2, the TolC protein is involved in the secretion of ExpE1 into the growth medium.

A visual inspection of a Coomassie blue staining of the extracellular proteins recovered from morpholinepropanesulfonic acid (MOPS)-buffered medium of SmLM8311 and SmLM032 shows that at least three protein bands approximately 52,75 , and $90 \mathrm{kDa}$ in size were consistently absent from the supernatant of the tolC mutant strain (Fig. 2). The identity of these proteins was determined by peptide mass fingerprinting and revealed that the $52-\mathrm{kDa}$ protein is $\mathrm{ExsH}$ and the 75- and 90-kDa proteins are encoded by ORF SMc04171. The product of SMc04171 is homologous to hemolysin-type calcium-binding proteins, having 13 glycine-rich nonapeptide repeats with the consensus GGXGXDXXX (no degeneracy allowed) distributed all along the protein sequence (between amino acid 53 and 464 in a total of 548 amino acids). SMc04171 protein shows a predicted molecular weight of $55 \mathrm{kDa}$ and an isoelectric point of 3.9; however, it is not unusual that this type of acidic protein shows altered mobility in gel electrophoresis (Kaufmann et al.

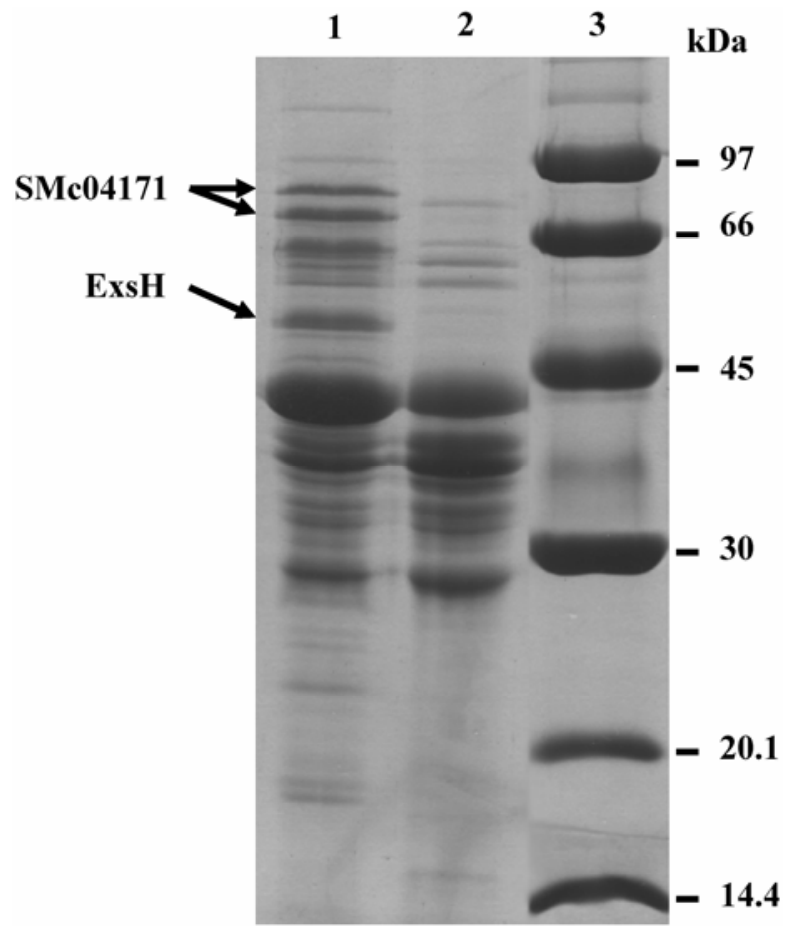

Fig. 2. Coomassie blue sodium dodecyl sulfate polyacrylamide gel electrophoresis displaying approximately $10 \mu \mathrm{g}$ of the extracellular proteins recovered from the supernatants of SmLM8311 (expA3 exoY mucR) (lane 1) and SmLM032 (tolC::pLS378 exoY mucR) (lane 2) grown in morpholinepropanesulfonic acid-buffered medium supplemented with $0.1 \mathrm{mM}$ phosphate. The protein bands missing in the tolC mutant strain that were identified are indicated by an arrow.
1984; Moreira et al. 2000). It also can be hypothesized that this protein may be targeted by post-translational modification such as acylation, as was described for hemolysin of E. coli and an adenylate cyclase of Bordetella pertussis, two other proteins containing glycine-rich calcium-binding nonapeptide repeats (Basar et al. 2001; Stanley et al. 1994).

\section{The $S$. meliloti tolC mutant is unable}

to secrete succinoglycan (EPS I) and galactoglucan (EPS II).

The possible involvement of the protein TolC in the biosynthesis of the EPS I and EPS II exopolysaccharides was evaluated. To assess for the presence of EPS I, strains were grown in liquid GMS medium for 3 days and the amount of total carbohydrate present in the supernatant was determined. The results obtained indicated a low amount of sugars for the tolC mutant SmLM030 supernatant (10 mg/liter), contrasting with the higher values for the wild-type strain $(820 \mathrm{mg} / \mathrm{liter})$ and complemented mutant strain (760 mg/liter) (Table 3). Using gel filtration chromatography, HMW and LMW fractions present in the culture supernatant of the different strains were separated. No HMW polymer was recovered from the tolC mutant strain, contrasting with both the wild-type Sm2011 and the complemented mutant strain SmLM030/pLM47-2 (Table 3). To determine whether the LMW fraction obtained from SmLM030 was LMW EPS I, the glucose and galactose content was quantified and only glucose was detected (Table 3 ).

To study the involvement of TolC in EPS II biosynthesis, $S$. meliloti strains carrying mutations in exoY and mucR genes were used and were grown in MOPS-buffered medium supplemented with $0.1 \mathrm{mM}$ phosphate, which was previously demonstrated to give a maximum expression of the exp genes (Ruberg et al. 1999). Under these conditions, the total sugar content of the culture supernatant after 10 days of growth showed $476 \mathrm{mg} / \mathrm{liter}$ for the EPS II-producing strain RmAR9007 TD101 and $47 \mathrm{mg} /$ liter for the SmLM032 mutant strain (Table 3). The complementation of SmLM032 with the plasmid pLM47-2 rescued EPS II production of this strain as demonstrated by the total sugars obtained of $438 \mathrm{mg} /$ liter. The negative control strain SmLM8311 showed total sugars of 17 $\mathrm{mg} / \mathrm{liter}$. The chromatographic analysis showed that no HMW fraction was in the culture supernatant of the tolC mutant strain SmLM032 but strain SmAR9007 TD101 and SmLM032/pLM47-2 showed both HMW and LMW fractions (Table 3). To confirm that the HMW fraction produced by the strains contained EPS II, the glucose and galactose content was quantified. The HMW fractions from RmAR9007 TD101 and SmLM032/pLM47-2 contained glucose and galactose in a ratio of approximately 1:1. The LMW fraction from the tolC mutant strain and SmLM8311 contained only glucose.

\section{The $S$. meliloti tolC mutant is impaired \\ in symbiosis with the host plant.}

The symbiotic properties of $S$. meliloti strains were analyzed in plant assays with aseptically grown Medicago sativa plants. After 5 weeks of inoculation, the plants inoculated with

Table 3. Analysis of culture supernatants by gel filtration chromatography and sugar content ${ }^{\mathrm{a}}$

\begin{tabular}{|c|c|c|c|c|c|}
\hline Strain & Genotype & Glucose equivalents (mg/liter) & HMW fraction & LMW fraction & Glc/Gal (\%) \\
\hline Sm2011 & Wild type & 820 & + & + & nd \\
\hline SmLM030 & tolC::pLS378 & 10 & - & + & $100 / 0$ \\
\hline SmLM030/pLM47-2 & tolC::pLS378/tolC & 760 & + & + & nd \\
\hline RmAR9007 TD101 & exoY mисR & 476 & + & + & $51 / 49$ \\
\hline SmLM032 & tolC::pLS378 ехоY тисR & 47 & - & + & $100 / 0$ \\
\hline SmLM032/pLM47-2 & tolC::pLS378/tolC ехоY тисR & 438 & + & + & $52 / 48$ \\
\hline SmLM8311 & exoY тисR expA3 & 17 & - & + & $100 / 0$ \\
\hline
\end{tabular}

${ }^{\text {a }} \mathrm{HMW}=$ high molecular weight, $\mathrm{LMW}=$ low molecular weight, $\mathrm{Glc} / \mathrm{Gal}=$ glucose/galactose, and nd = not determined. 
SmLM051 were healthy and the ones inoculated with SmLM030 were smaller and yellowish (data not shown). The nodulation rate was assessed by counting the number of nodules at particular time points after inoculation. Mutant SmLM030 has a much lower number of nodules when compared with the SmLM051 strain (Fig. 3E). In fact, half of the plants inoculated with SmLM030 showed one or two nodules per plant and the other half did not show nodules at all. In contrast, the SmLM030 tolC mutant complemented with plasmid pLM47-2 showed a slight increase of the nodule number when compared with the wild-type SmLM051 (Fig. 3E). To evaluate whether the symbiotic phenotype seen for SmLM030 was due to the lack of EPS I, the number of nodules elicited by the tolC mutant was compared with the number elicited by the EPS I deficient exoY mutant and exoY tolC double mutant. After 5 weeks of inoculation, the exoY mutant showed an average of 16 nonfixing nodules/plant compared with 1 nonfixing nodule/plant of the exoY tolC double mutant (Fig. 3E). The visual inspection of the roots inoculated with mutant SmLM030 showed that this strain induced the formation of brownish-white nonfixing (ineffective) round or slightly elongated nodules whereas the wild-type strain SmLM051 showed normal nitrogen-fixing nodules (Fig. 3A and C). The exoY tolC double mutant revealed swelling structures that surround the root (pseudonodules) in contrast to the exoY mutant where the white nodules protrude from the root in one direction only (Fig. 3B and D).

To determine whether the ineffective nodules of exoY, tolC, and exoY tolC mutants had bacteria inside, they were crushed in the presence of TY medium and this suspension was plated on TY medium with appropriate antibiotics. Approximately $10^{4}$ cells/nodule were obtained for nodules elicited by the wild-type strain, the exoY, and SmLM030 mutants. Four pseudonodules induced by the exoY tolC mutant also were tested; two of them had between 20 and 300 cells and the other two did not have viable bacteria.

\section{Phylogenetic analysis of $S$. meliloti TolC.}

A phylogenetic analysis with characterized members of the TolC family and with some of the strongest homologs (E value cutoff: $\left.1 \times 10^{-13}\right)$ at the amino acid level with $S$. meliloti TolC was performed. Proteins clustered in four different groups, which correlates to some extent with the type of compounds secreted (Fig. 4). Group I includes some characterized proteins such as OprJ and OprN from Pseudomonas spp. and SmeC from Stenotrophomonas spp. involved in the efflux of multiple drugs. Interestingly, several NodT homologs from the Rhizobiaceae family (including three proteins from $R$. leguminosarum bv. viciae, two from $R$. etli, and one from Bradyrhizobium japonicum) also clustered in group I (Fig. 4). Almost all of the proteins from group I have a predicted lipid attachment site. $\operatorname{NodT}_{\mathrm{b}}$ from $R$. leguminosarum was suggested to be involved in Nod factors secretion, but no experimental evidence was obtained (Rivilla et al. 1995). Group $\mathrm{III}_{\mathrm{a}}$ includes $S$. meliloti TolC together with other TolC-like proteins from $\alpha$-proteobacteria. Among the Rhizobiaceae family, two proteins from B. japonicum, one from a Mesorhizobium sp., and one from $S$. medicae also clustered in this group (Fig. 4). With the exception of S. meliloti TolC, the only characterized TolC homolog from group $\mathrm{III}_{\mathrm{a}}$ is BepC from Brucella suis. Unlike $S$. meliloti TolC, which is implicated in protein secretion and small molecules efflux, BepC was implicated only in the efflux of small and relatively hydrophobic compounds (Posadas et al. 2007). Group $\mathrm{III}_{\mathrm{b}}$ includes the characterized proteins $\mathrm{RsaF}_{\mathrm{a}}$ and $\mathrm{RsaF}_{\mathrm{b}}$ from the $\alpha$-proteobacteria Caulobacter crescentus (Fig. 4). Both proteins are required to assemble a fully functional type I secretion system for the secretion of the crystalline S-layer RsaA protein (Toporowski et al. 2004). Cluster III, including proteins involved in protein secre- tion only, small molecules efflux only, or both, is nevertheless well separated from those that participate in protein secretion only (group $\mathrm{IV}_{\mathrm{a}}$ ), as well as multifunctional proteins such as TolCs from E. coli and Salmonella typhimurium or HasF from Serratia marcescens (group $\mathrm{IV}_{\mathrm{b}}$ ). TolC from Erwinia chrysanthemi and $X$. fastidiosa, also from group $\mathrm{IV}_{\mathrm{b}}$, are demonstrated to be involved in the efflux of small toxic compounds; however, the possibility of mediating protein secretion also cannot be excluded (Barabote et al. 2003; Reddy et al. 2007).

The clusters obtained with the TolC proteins from the several Rhizobiaceae family members do not allow any distinction between symbionts that invade indeterminate legumes (e.g., Sinorhizobium spp. or R. leguminosarum) and those that invade determinate legumes (e.g., Mesorhizobium spp., Bradyrhizobium spp., or $R$. etli). Both determinate and indeterminate legume symbionts clustered together in groups I and $\mathrm{III}_{\mathrm{a}}$ (Fig. 4). The number of TolC homologs per species included also does not correlate with the type of host plant. Sinorhizobium and Mesorhizobium spp. have one TolC homolog, R. etli has two, $R$. leguminosarum has three, and Bradyrhizobium spp. have three to five TolC homologs (Fig. 4).

\section{DISCUSSION}

In this work, we have determined the possible roles of the Sinorhizobium meliloti TolC protein with respect to transported substrates and roles in nitrogen fixation symbiosis. TolC proteins are recruited by different types of inner membrane transport systems like the ABC-MFP, RND-MFP, or MFS-MFP to secrete proteins and other substrates or pump antimicrobial drugs outside the cell (Delepelaire 2004; Koronakis 2003). The phylogenetic analysis clusters $S$. meliloti TolC with proteins from other $\alpha$-proteobacteria and only two have been experimentally characterized: BepC from B. suis, which was demonstrated to be involved in the efflux of small compounds (Posadas et al. 2007), and $\mathrm{RsaF}_{\mathrm{a}} / \mathrm{RsaF}_{\mathrm{b}}$ from $C$. crescentus, involved in the secretion of the S-layer protein RsaA (Toporowski et al. 2004). A mutation in the tolC gene from $S$. meliloti strongly increased the sensitivity to SDS and deoxycholate (DOC) and to plant-derived chemicals such as Berberine and Genistein. These results suggested the possible involvement of $S$. meliloti TolC in the process of pumping out small and hydrophobic compounds, probably together with RND-MFP or MFS-MFP transporters.

Protein secretion is also an important feature for $S$. meliloti, and at least four ABC transporters with the COG4618 (ABC type protease/lipase transport system, ATPase component), including ExpD1, PrsD, SMc04207, and SMc03147, are present in the genome. PrsD/PrsE and ExpD1/ExpD2 were implicated in the secretion of ExsH and ExpE1 proteins, respectively, but the outer membrane component of these type I secretion systems hasn't yet been assigned to either of them (Moreira et al. 2000; York and Walker 1997). Our immunodetection experiments clearly demonstrate the involvement of TolC protein in the secretion of both ExsH and ExpE1 to the extracellular medium. By comparing the extracellular proteins of the wild-type strain with the tolC mutant strain, we also were able to identify a new protein, encoded by ORF SMc04171, possibly secreted by a TolC-dependent type I secretion system. The common features of these three proteins are the GGXGXDXXX glycine-rich nonapeptide repeats, present in 1 copy in ExsH, 10 copies in ExpE1, and 13 copies in SMc04171 (if no degeneracy is allowed), and a $\mathrm{C}$-terminal secretion signal. The analysis of the $S$. meliloti 1021 genome reveals the presence of at least 15 other proteins with nonapeptide repeats varying in number from 2 to more than 30 (Delepelaire 2004), and it is possible that some of them may also be substrates for TolC-dependent 
secretion systems. In addition, Hoang and associates (2004) identified that eight of these genes encoding proteins with nonapeptide repeats, including expE1, exsH, and SMc04171, among others, had a downregulated expression in the absence of the ExpR regulator and the sin quorum-sensing dependent $\mathrm{N}$-acyl homoserine lactones (AHL). The Sm2011 strain used in this work is able to produce AHL but is $\operatorname{expR}$ deficient, leading probably to a lower expression of many genes, including the genes encoding proteins with nonapeptide repeats. This can possibly explain the sole identification of three proteins (ExpE1, ExsH, and SMc04171) absent from the tolC mutant supernatant. Two other proteins with glycine-rich nonapeptide repeats, encoded by ORF SMc03108 and ORF SMb20838, were recently reported as being upregulated in an $S$. meliloti mutant for the two-component sensory histidine kinase CbrA (Gibson et al. 2007). CbrA seems to play an important role in regulating stationary-phase physiology in $S$. meliloti and a cbrA mutant is probably locked into a physiological state specialized for early infection thread invasion, being unable to properly differentiate into bacteroids. The fact that SMc03108 and SMb20838 exhibited increased expression in this "locked" state suggests that they may contribute to infection thread growth.

Due to the essential role of ExpE1 in EPS II biosynthesis and ExsH in the depolymerization of HMW-EPS I to obtain LMW forms, we evaluated the ability of the $S$. meliloti tolC mutant to produce both exopolysaccharides. As expected, no EPS II was secreted by the tolC mutant because this strain is unable to secrete ExpE1. Therefore, TolC seems to have an indirect role in EPS II biosynthesis. The lack of EPS I in the culture supernatant of the tolC mutant was an interesting and unexpected observation; however, it cannot be attributed to the lack of ExsH protein. In fact, the $S$. meliloti exs $H$ mutant shows a strong reduction in LMW-EPS I fraction but produces increased levels of HMWEPS I (York and Walker 1997). To our knowledge, the involvement of TolC protein members in the biosynthesis of polysaccharides was never reported before. Like many other heteropolysaccharides, succinoglycan from $S$. meliloti is synthesized by a Wzy-dependent process, with ExoP being the protein determin- ing polysaccharide chain length, ExoQ being responsible for polymerization of the repeat-units, and ExoT possibly being a translocase of the repeat-units. The biosynthesis of HMW-EPS I needs ExoP, ExoQ, and possibly ExoT. The biosynthesis of LMW EPS I seems to proceed in the presence of ExoP and ExoT, with no requirement for ExoQ (Gonzalez et al. 1998), but the mechanistic details are not yet known. The translocation of EPS I to the outside of the cell is probably mediated by ExoF. This protein is homologous to dedicated outer-membrane lipoproteins from the outer membrane auxiliary (OMA) family that forms channels for polysaccharide translocation (Whitfield 2006). These OMA proteins seem to be different from TolC in the overall structure and function and it is unlikely that TolC may have a direct role in this final step of polysaccharide biosynthesis or secretion; however, we cannot exclude the possibility that it may interact, for example, with ExoF and promote EPS I secretion. Another possible explanation for the lack of EPS I by the tolC mutant is that, in the absence of TolC from the outer membrane, this structure may be destabilized and no proper assembly of the protein complex involved in polysaccharide secretion occurs. Alternatively, the role of TolC in EPS I may be mediating the secretion of unknown proteins required for the biosynthesis of this polysaccharide. From the remaining exo and exs genes directing the biosynthesis of EPS I, only the ExoK endo- $\beta-1,3-1,4$ glycanase is known to be secreted but very likely by a type II secretion system (Becker et al. 1993; York and Walker 1997); in addition, the exoK mutant strain is able to produce EPS I (York and Walker 1997). The other protein with a role in EPS I biosynthesis is EglC, a putatively type I-secreted endoglycanase which shows a reduction of 14\% of LMW-EPS I when mutated; however, the total amount of EPS in the culture supernatant of this mutant was still comparable with the one of the S. meliloti wild-type strain (Sharypova et al. 1999).

Our observations indicate that the $S$. meliloti tolC mutant induces none or a very reduced number of nodules in the roots of $M$. sativa and that these few nodules have round or slightly elongated shape and are ineffective in nitrogen fixation. The inability of the tolC mutant to establish an effective symbiosis with alfalfa could be related to a higher sensitivity to plant-
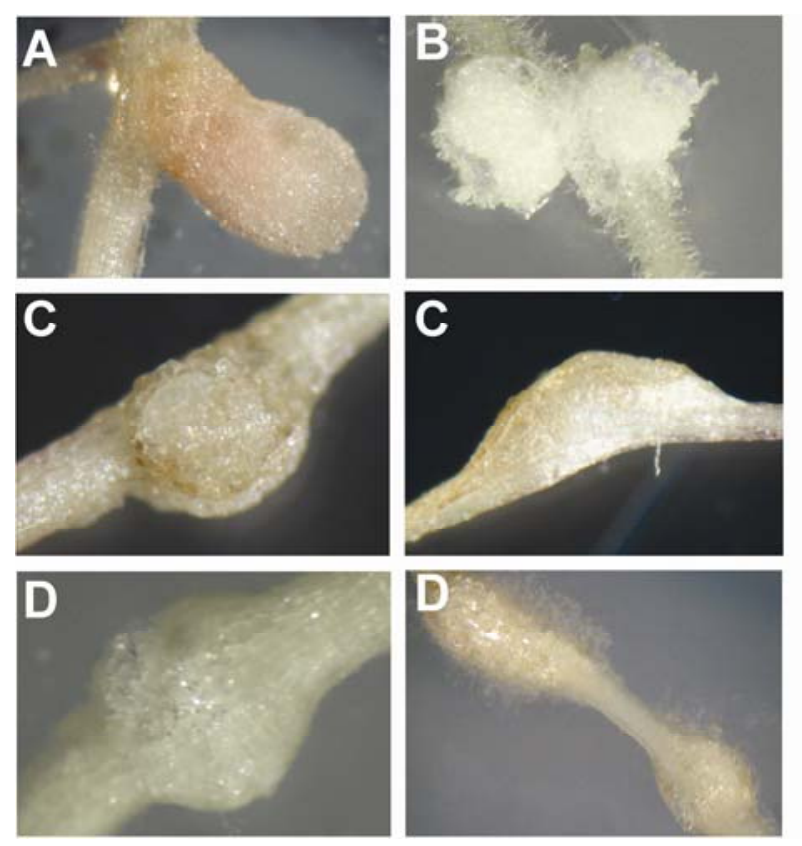

E

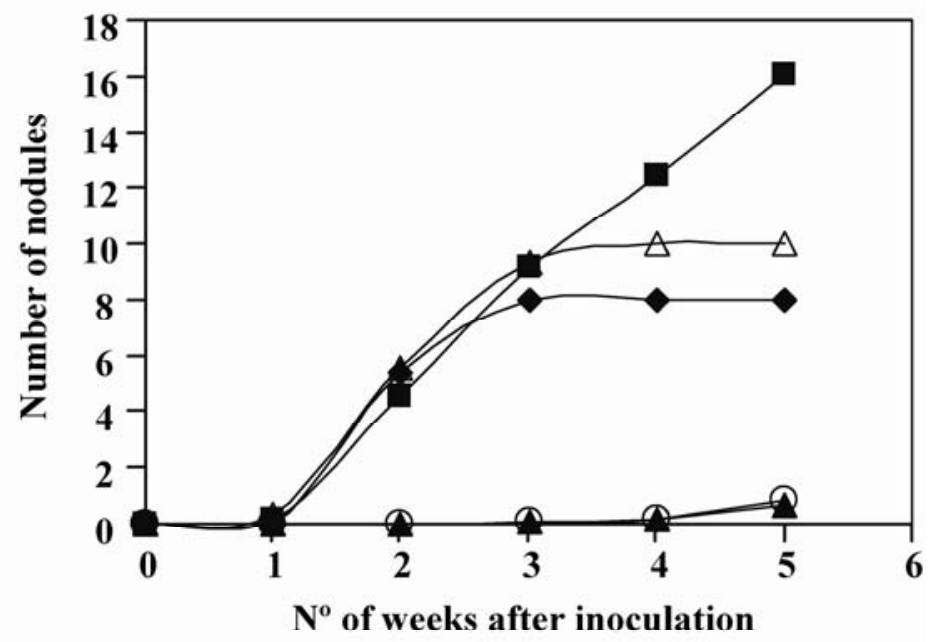

Fig. 3. Sinorhizobium meliloti tolC mutant is unable to establish nitrogen fixing nodules in Medicago sativa. Root nodules of $M$. sativa inoculated with the A, SmLM051; B, SmAR9007; C, SmLM030; and D, SmLM031. E, Rate of nodules induced by strains SmLM051 ( $\bullet$ ), SmLM030 (A), SmLM030 complemented in trans with plasmid pLM47-2 expressing the tolC gene $(\triangle)$, RmAR9007 ( $\mathbf{\square})$, and SmLM031 (O). The values shown represent the average number of nodules per plant. Data are the average of 20 replicates. 
derived chemicals and, eventually, to a lower capacity to withstand oxidative burst or osmotic stress within the host environment. The lower number of immature nodules obtained could reflect the inability of the mutant to establish chronic infections or survive within the host environment. Indeed, our results indicate that the tolC mutant strain was more sensitive both to oxidative and osmotic stress ex planta. The lack of EPS I biosynthesis by the tolC mutant strain could also explain the deficient symbiotic phenotype observed but, interestingly, the type and amount of nodules obtained were very different from the ones of the exoY mutant, deficient in EPS I biosynthesis only. In addition, the exoY tolC double mutant shows an even more severe phenotype, with pseudonodule-like structures containing no or few bacteria. The fact that bacteria were isolated from the nodules of exoY and the tolC mutants does not necessarily mean colonization. It is known that the exoY mutant is unable to initiate the formation of infection threads and colonize the nodule yet, despite that, Cheng and Walker (1998) found that parts of the surface of some of the exoY mutant elicited nodules were colonized by a single layer of bacterial cells

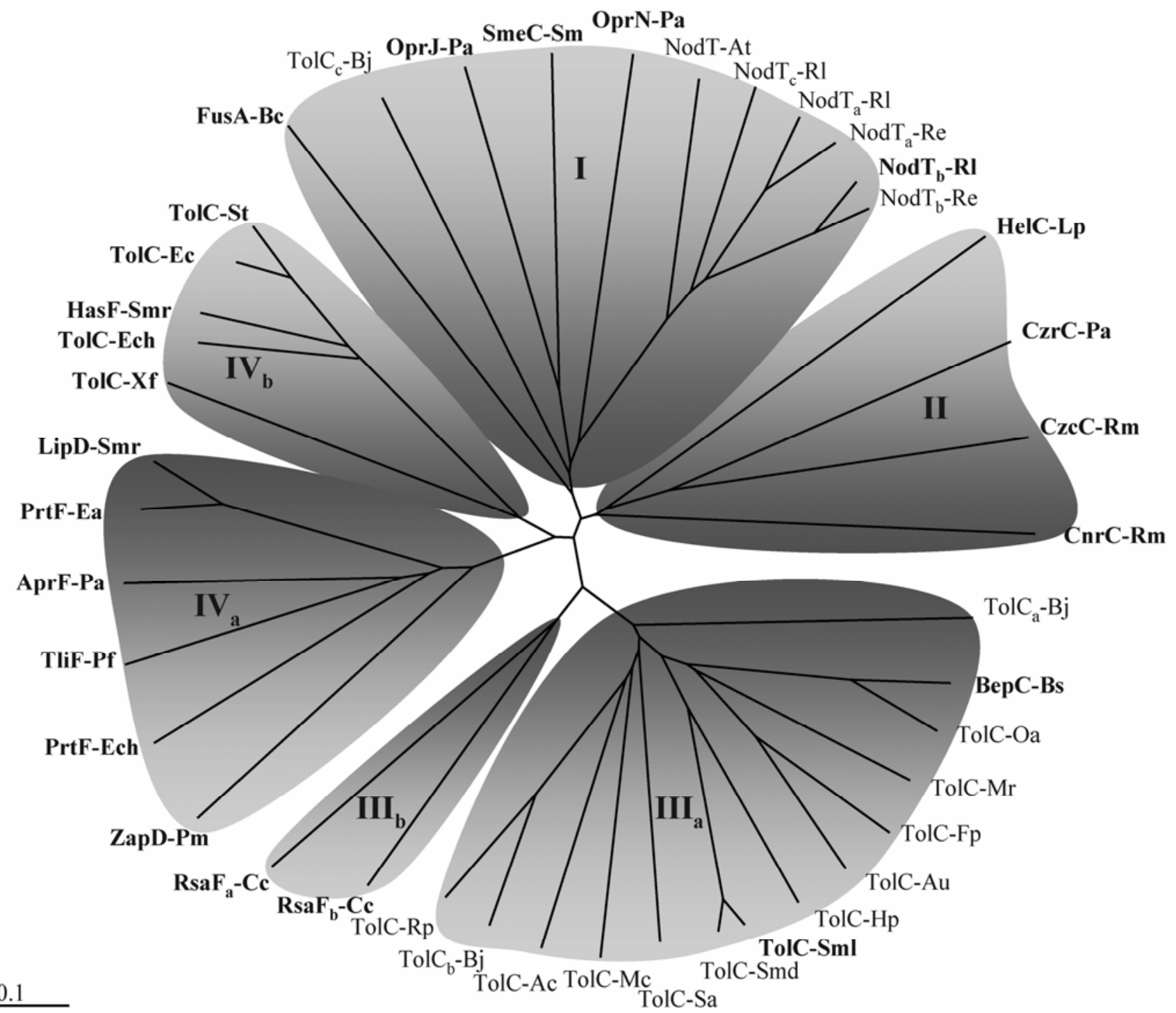

Fig. 4. Phylogenetic tree comprising 42 members of the TolC family. Included are proteins of known function (represented in bold characters) and proteins highly homologous to Sinorhizobium meliloti TolC that were aligned by ClustalX and sorted by Tree View. The clusters obtained correlate with substrate specificity, being able to distinguish proteins involved in drug or other small molecules efflux (group I) and cation efflux (group II), and a bigger group involved in protein secretion only (group $\mathrm{IV}_{\mathrm{a}}$ ) or multifunctional (group $\mathrm{IV}_{\mathrm{b}}$ ). Group III includes many uncharacterized proteins, with group III $\mathrm{a}_{\mathrm{a}}$ proteins being involved in protein secretion and group $\mathrm{III}_{\mathrm{b}}$ including proteins that are involved in protein secretion only or that are multifunctional. The TolC homologues included are: TolC-Mr, Mesorhizobium sp. (gi|110633922); TolC-Fp, Fulvimarina pelagi (gi|114707212); TolC-Mc, Methylobacterium chloromethanicum (gi|156452498); TolC-Sa, Stappia aggregata (gi|118589088); TolC-Ac, Azorhizobium caulinodans (gi|158424441); TolC ${ }_{\mathrm{a}}$-Bj, Bradyrhizobium japonicum (gi|27378146); TolC $\mathrm{b}_{\mathrm{b}} \mathrm{Bj}$, B. japonicum (gi|27379584); TolC $\mathrm{C}_{\mathrm{c}}-\mathrm{Bj}$, B. japonicum (gi|27379566); NodT-At, Agrobacterium tumefaciens

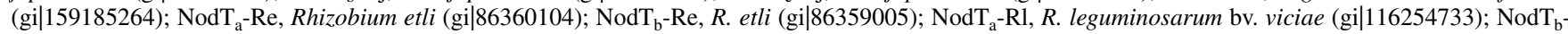
Rl, R. leguminosarum bv. viciae (gi|116253616); NodT $-\mathrm{c} 1$, R. leguminosarum bv. viciae (gi|116254620); TolC-Hp, Hoeflea phototrophica (gi|163759466); TolC-Sml, Sinorhizobium meliloti (gi|15965267); TolC-Smd, S. medicae (gi|113872929); TolC-Au, Aurantimonas sp. (gi|90419371); TolC-Rp, Rhodopseudomonas palustris (gi|86750011); TliF-Pf, Pseudomonas fluorescens (gi|4063019); AprF-Pa, P. aeruginosa (gi|45282); CzrC-Pa, P. aeruginosa (gi|5921516); OprN-Pa, P. aeruginosa (gi|15597691); OprJ-Pa, P. aeruginosa (gi|116052739); PrtF-Ech, Erwinia chrysanthemi (gi|41550); PrtF-Ea, E. amylovora (gi|4826418); LipD-Smr, Serratia marcescens (gi|3080540); HasF-Smr, S. marcescens (gi|1405817); ZapD-Pm, Proteus mirabilis (gi|3493599); TolC-Ec, Escherichia coli (gi|90111528); TolC-St, Salmonella thyphimurium (gi|799383); TolC-Xf, Xylella fastidiosa (gi|71899951); CnrC-Rm, Ralstonia metallidurans (gi|521152); HelC-Lp, Legionella pneumophila (gi|54298314); FusA-Bc, Burkholderia cepacia (gi|242023); BepC-Bs, Brucella suis (gi|23347764); $\mathrm{RsaF}_{\mathrm{a}}-\mathrm{Cc}$, Caulobacter crescentus (gi|16125267); RsaF $-\mathrm{Cc}$, C. crescentus (gi|16125567); TolC-Oa, Ochrobactrum anthropi (gi|153009573); SmaC-Sm, Stenotrophomonas malthophilia (gi|5764626); CzcC-Rm, Ralstonia metallidurans (gi|1731916); TolC-Pc, Pectobacterium chrysanthemi (gi|15987119). 
within the nodule epidermis. Whether or not this happens in the nodules of the tolC mutant remains to be clarified. Taken together, the very low number of nodules induced by the tolC and the exoY tolC mutants compared with the exoY mutant suggests that TolC is probably involved in secretion of other molecules crucial to the symbiosis such as the Nod factors. Several studies report that nod gene mutants unable to secrete normal levels of Nod factors resulted in poor or no nodulation of the host plant (Cardenas et al. 1996; Djordjevic et al. 1985). Furthermore, it is well established that the NodI/NodJ transport system is involved in the secretion of Nod factors in $R$. leguminosarum and $R$. etli, but no outer membrane component has been attributed (Cardenas et al. 1996; Spaink et al. 1995). $S$. meliloti also possesses the NodI/NodJ proteins and it is likely that ORF SMc02082, being the only TolC-like protein in this strain, may mediate Nod factor secretion.

The evidence presented in this article points out several possibilities for the involvement of the TolC protein in symbiosis. TolC may participate in the efflux of antimicrobial compounds produced by the host plant, resistance to osmotic or oxidative stress, polysaccharide biosynthesis, and the secretion of proteins or other molecules, such as Nod factors, relevant for the symbiosis. Further studies have to be performed to understand in more detail its crucial role in the outer membrane of $S$. meliloti and its implications in cell physiology during the various stages of symbiotic development.

\section{MATERIALS AND METHODS}

\section{Microbiological methods.}

Bacterial strains and plasmids used in this study are listed in Table 4. Escherichia coli strains were grown in Lennox Broth (Sambrook et al. 1989) at $37^{\circ}$ C. S. meliloti strains were grown in TY medium (Beringer 1974), GMS medium (York and Walker 1997), or MOPS-buffered medium ( $\mathrm{pH}$ 7.4) supplemented with $0.1 \mathrm{mM}$ phosphate (Neidhardt et al. 1974) at $30^{\circ} \mathrm{C}$. Antibiotics were supplemented as required at the following concentrations: for S. meliloti, spectinomycin (Spc) at 200 $\mu \mathrm{g} / \mathrm{ml}$, streptomycin $(\mathrm{Sm})$ at $600 \mu \mathrm{g} / \mathrm{ml}$, tetracycline $(\mathrm{Tc})$ at 8 $\mu \mathrm{g} / \mathrm{ml}$, gentamicin $(\mathrm{Gm})$ at $40 \mu \mathrm{g} / \mathrm{ml}$, and neomycin $(\mathrm{Nm})$ at $120 \mu \mathrm{g} / \mathrm{ml}$; for E. coli, tetracycline at $10 \mu \mathrm{g} / \mathrm{ml}$ and kanamycin $(\mathrm{Km})$ at $50 \mu \mathrm{g} / \mathrm{ml}$. Stock solutions at $10 \mu \mathrm{mg} / \mathrm{ml}$ were prepared for Genistein (4,5,7-trihydroxyisoflavone), $p$-Coumaric acid, and Berberine (5,6-dihydro-9,10-dimethoxybenzo-1,3-benzodioxoloquinolizimium). Berberine was dissolved in water, Genistein was dissolved in $50 \mathrm{mM} \mathrm{NaOH}$, and $p$-Coumaric acid was dissolved using $95 \%$ ethanol.

\section{DNA manipulations.}

Preparation of plasmid DNA, DNA restriction, agarose gel electrophoresis, cloning, and transformation of $E$. coli cells were carried out according to established protocols (Sambrook et al. 1989). Southern hybridizations were performed as described by Kessler (1992). Total DNA from rhizobia was isolated as described by Meade and associates (1982). Mutations were transferred between $S$. meliloti strains by phage $\Phi \mathrm{M} 12$ mediated general transduction as described by Finan and associates (1984).

\section{Construction of a tolC insertion mutant.}

An internal fragment of $891 \mathrm{bp}$ starting at position 441 downstream of the Sm1021 tolC gene start codon (ORF SMc02082) was amplified by PCR using primers tolC-up (5'-GATCAGCA GGTCGTTTCCAT) and tolC-dn (5'-CTTGACGGCCTCGTA ATGTT) and using Sm2011 genomic DNA as template. The amplified product was cloned into the suicide vector

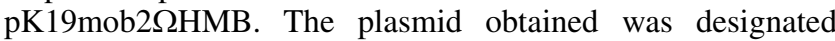
pLS378 and was mobilized from strain E. coli S17-1 (Simon et al. 1983) to $S$. meliloti 2011. Plasmid integration into the genome and homogenotization was verified by Southern hybridization and by PCR. The same procedure was used to obtain mutant SmLM051 by insertion of plasmid pLM51-5 into Sm2011. The internal fragment of ORF Y21420 was amplified by using PCR primers Y21420-up (5'-CCGAAGCTTCATCGA GGTGGTGA; restriction sites are in italic) and Y21420-low (5'-GCAAAGCTTCTGGATGTCGAACT).

In order to complement the $S$. meliloti tolC mutant, $1,672 \mathrm{bp}$ containing tolC under the control of its own promoter was

Table 4. Strains, plasmids, and phage

\begin{tabular}{|c|c|c|}
\hline Strain, plasmid, phage & Relevant characteristics $^{\mathbf{a}}$ & Source, reference \\
\hline \multicolumn{3}{|l|}{ Strain } \\
\hline \multicolumn{3}{|l|}{ Sinorhizobium meliloti } \\
\hline Sm2011 & Wild-type, $\mathrm{Nx}^{\mathrm{r}} \mathrm{Sm}^{\mathrm{r}}$ & Casse et al. 1979 \\
\hline Sm1021 & Wild-type, $\mathrm{Su} 47 \mathrm{Sm}^{\mathrm{r}}$ & Leigh et al. 1985 \\
\hline Rm101 & $\mathrm{Sm} 2011, \mathrm{Spc}^{\mathrm{r}}$ cassette of $\mathrm{pHP} 45 \Omega$ inserted into the PmacI site of $m и с R($ mисR $101-\mathrm{Spc})$ & Becker et al. 1997 \\
\hline RmAR9007 & Sm2011, exoY-lacZlaacC1 & Keller et al. 1995 \\
\hline RmAR9007 TD101 & Sm2011, exoY-lacZlaacC1 mucR-spc & Quester and Becker 2004 \\
\hline SmLM8311 & RmAR9007 TD101, expA3::Tn5 & Moreira et al. 2000 \\
\hline SmLM9836 & Sm2011, $\Delta \operatorname{expE1~exoY-lacZ/aacC1~mисR-spc~}$ & Moreira et al. 2000 \\
\hline $\mathrm{RmH} 29 \mathrm{r}$ & Sm1021, exsH-lacZ/aacC1, lacZ-aacC1 in antisense orientation to exsH & This work \\
\hline SmAC07-1 & RmH29r exoY::Tn5 & This work \\
\hline SmLM051 & Sm2011, pLM51-4 integrated into the Y21420 gene region & This work \\
\hline SmLM030 & Sm2011, pLS378 integrated into the $t o l C$ gene region & This work \\
\hline SmLM031 & Sm2011, exoY-lacZ/aacC1 tolC::pLS378 & This work \\
\hline SmLM032 & Sm2011, exoY-lacZ/aаcC1 mисR-spc tolC::pLS378 & This work \\
\hline \multicolumn{3}{|l|}{ Escherichia coli } \\
\hline XL-1 Blue & recA1 lac $\left(\mathrm{F}^{\prime} \operatorname{proAB}\right.$ lac $\left.\mathrm{I}^{\mathrm{q}} \mathrm{Z} \Delta \mathrm{M} 15 \mathrm{Tn} 10\left(\mathrm{Tc}^{\mathrm{r}}\right)\right)$ thi & Bullock et al. 1987 \\
\hline S17-1 & E. coli 294 , thi RP4-2-Tc::Mu-Km::Tn7 chromosomally integrated & Simon et al. 1983 \\
\hline \multicolumn{3}{|l|}{ Plasmid } \\
\hline pPHU231 & broad host range low-copy vector, $\mathrm{Tc}^{\mathrm{r}}$ & Reyes et al. 1996 \\
\hline 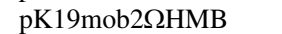 & pK19mob2 derivative with unique $H i n \mathrm{dIII}, B s r \mathrm{GI}$, and $M f \mathrm{eI}$ sites, followed by a terminator, $\mathrm{Km}^{\mathrm{r}}$ & Sharypova et al. 2006 \\
\hline pLS378 & pK19mob2 2 HMB containing a 1,368 -bp internal fragment of tolC & This work \\
\hline pLM47-2 & pPHU231 containing a 1,672-bp fragment with the tolC gene under the control of its own promoter & This work \\
\hline pLM51-4 & pK19mob containing 628-bp internal fragment of Y21420 gene, $\mathrm{Km}^{\mathrm{r}}$ & This work \\
\hline \multicolumn{3}{|c|}{ 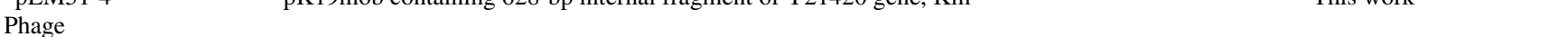 } \\
\hline$\Phi M 12$ & S. meliloti transducing phage & Finan et al. 1984 \\
\hline
\end{tabular}

${ }^{\mathrm{a}} \mathrm{Nx}^{\mathrm{r}}, \mathrm{Sm}^{\mathrm{r}}, \mathrm{Spc}^{\mathrm{r}}, \mathrm{Tc}^{\mathrm{r}}$, and $\mathrm{Km}^{\mathrm{r}}=$ resistant to nalidixic acid, streptomycin, spectinomycin, tetracycline, and kanamycin, respectively. 
amplified by PCR using primers PtolC-up (5'-CCCGAATTCT GAGGTAGCTCA) and PtolC-low (5'-TTTGAATTCCGAACT GGCTGA) and Sm2011 genomic DNA as a template. The amplified fragment was inserted into the EcoRI site of broad host range vector pPHU231 and the resulting plasmid was named pLM47-2.

\section{Zone inhibition assays.}

Cultures of respective strains were grown overnight and approximately $10^{6}$ cells were plated in TY agar containing appropriate selection antibiotics. Sterile paper disks $6 \mathrm{~mm}$ in diameter were placed on the surface of the agar. A total of 30 $\mu \mathrm{l}$ of novobiocin $(20 \mathrm{mg} / \mathrm{ml})$, SDS (10\% [wt/vol]), and DOC (5\% [wt/vol]); $8 \mu \mathrm{l}$ of $\mathrm{H}_{2} \mathrm{O}_{2}$; and 10,50 , and $100 \mathrm{mM}$ or methyl violagen (paraquat) up to $1 \mathrm{M}$ was pipetted onto separate disks. The plates were incubated for $48 \mathrm{~h}$ and the diameters (in millimeters) of the zones of inhibition measured.

\section{Determination of MIC.}

MIC assays were performed in a final volume of $0.2 \mathrm{ml}$ in 96-well microtiter plates. The hydrophobic agents or $\mathrm{NaCl}$ under test were serially diluted in GMS broth containing the appropriate selection antibiotics for the different strains. Controls for the solvents used to dissolve the hydrophobic chemicals were also included. Bacteria from an overnight culture were inoculated at a final concentration of $10^{6}$ cells $/ \mathrm{ml}$. The microtiter plates were shaken at $250 \mathrm{rpm}$ at $30^{\circ} \mathrm{C}$ for $36 \mathrm{~h}$. The MIC was determined as the lowest concentration of the substance which prevented growth after $36 \mathrm{~h}$.

\section{Analysis of proteins}

\section{in cell extracts and culture supernatants.}

$S$. meliloti strains in the late exponential growth phase (optical density at $600 \mathrm{~nm} 1.5$ to 2.0) were grown in GMS medium or MOPS-buffered medium supplemented with $0.1 \mathrm{mM}$ phosphate. Cells were centrifuged for $5 \mathrm{~min}$ at $18,000 \times g$ at $4^{\circ} \mathrm{C}$ and the pellets were solubilized in SDS sample buffer to yield a preparation of total cellular proteins. To assess the presence of ExpE1 or identify extracellular proteins absent from the tolC mutant strain, culture supernatants $(150 \mathrm{ml})$ were separated from the cells by centrifugation $\left(20,000 \times g, 4^{\circ} \mathrm{C}, 15\right.$ min) followed by filtration through a $22-\mu \mathrm{m}$ filter and lyophi-

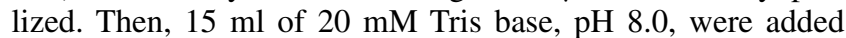
and proteins were concentrated by filtration (Ultrafree Concentrator) and mixed with SDS sample buffer. To assess the presence of ExsH, $20 \mu \mathrm{l}$ of cell-free supernatant were directly mixed with SDS sample buffer. Protein concentrations were determined by using the Bio-Rad protein assay with bovine serum albumin as a standard (Bradford 1976).

\section{Immunodetection of proteins.}

Proteins separated by $12.5 \%$ polyacrylamide gels (SDSpolyacrylamide gel electrophoresis) were electroblotted onto nitrocellulose membranes by the procedure of Towbin and associates (1979). Immunodetection was performed according to standard protocols (Harlow and Lane 1988). The antibody against ExpE1 was prepared as described by Moreira and associates (2000). The antibody against ExsH was used as described by York and Walker (1998).

Proteins were identified by peptide mass fingerprinting as previously described by Watt and associates (2005).

\section{Production and analysis of extracellular EPSs from bacterial culture supernatants.}

To assess succinoglycan or galactoglucan production, the different $S$. meliloti strains were cultivated in GMS medium or MOPS-buffered medium supplemented with $0.1 \mathrm{mM}$ phosphate for 3 and 10 days, respectively, at $30^{\circ} \mathrm{C}$ with orbital agitation. Bacterial cells were removed by centrifugation $(20,000 \times g, 15$ $\mathrm{min}$ ) and the culture supernatants were desalted by dialysis (molecular mass cutoff $1 \mathrm{kDa}$ ) against water for 3 days, followed by lyophilization. HMW and LMW fractions were separated by gel filtration chromatography (twice on GFC 4000-8 and once on GFC 300-8, column size 300 by $7.7 \mathrm{~mm}$; Machery-Nagel; flow rate, $0.8 \mathrm{ml} / \mathrm{min} ; 200 \mathrm{mM}$ sodium chloride, $200 \mathrm{mM}$ sodium phosphate buffer, $\mathrm{pH}$ 7.0). Fractions were detected using a differential refraction index detector. Glucose and galactose content of the HMW and LMW fractions was quantified by enzymatic assays after hydrolysis with hydrochloric acid and subsequent neutralization (Beutler 1984; Kunst et al. 1984).

In order to determine the total carbohydrates present in the supernatant of strains grown in GMS medium, the polysaccharides were precipitated with $3 \%$ cetyl pyridinium chloride, air dried, and resuspended in the same volume of water, and the total sugars quantified by the HCl-L-Cysteine method (Chaplin and Kennedy 1986). The total carbohydrates present in the supernatant of strains grown in MOPS-buffered medium was done directly in the supernatant without further precipitation.

\section{Plant growth conditions.}

$M$. sativa genotype Europa seed were surface sterilized by concentrated sulfuric acid for $10 \mathrm{~min}$ and washed several times with large volumes of sterile water. Seed were kept at $4^{\circ} \mathrm{C}$ over a 2-day period and then allowed to germinate on $1.5 \%$ water agar plates at room temperature in the dark for $24 \mathrm{~h}$. Seedlings were then grown on nitrogen-free medium (Rolfe et al. 1980) and inoculated with overnight cultures of $S$. meliloti strains that were washed in distilled water. Each plate containing three $M$. sativa seedlings was inoculated with $200 \mu \mathrm{l}$ of cell suspension $\left(10^{4}\right.$ cells $)$. Plants were grown under a cycle of $16 \mathrm{~h}$ of light and $8 \mathrm{~h}$ of darkness for 5 weeks.

The nodules elicited by the strains under study were harvested from the roots of $M$. sativa, surface-sterilized with $70 \%$ ethanol for $1 \mathrm{~min}$, washed with sterile water, and crushed in TY medium. Bacterial suspensions recovered from the nodules were diluted and plated on TY plates containing the appropriate antibiotics.

\section{Phylogenetic analysis.}

Molecular evolutionary relationships between 42 proteins from the TolC family were examined by the neighbor-joining method of tree construction. Alignment of the proteins was performed with ClustalX (1.81). Phylogenetic tree was displayed by Tree View 1.6.6.

\section{ACKNOWLEDGMENTS}

We thank G. C. Walker (Massachusetts Institute of Technology, Cambridge, U.S.A.) for providing the antibody against ExsH and C. Eck (Technology Platform Genomics, Center for Biotechnology, Bielefeld University, Germany) for performing the protein identification. This work was supported by Fundo Europeu de Desenvolvemento Regional and Fundação para a Ciência e a Tecnologia (FCT), Portugal (contracts PTDC/AGRAAM/66977/2006, PTDC/AGR-GPL/70592/2006, POCTI/BME/44441/ 2002, POCTI/AGG/39533/2001, and a Ph.D. grant, SFRH/BD/16177/2004, to A. M. Cosme) and Bundesministerium für Bildung und Forschung: GenoMik Plus grant 0313805A, Germany.

\section{LITERATURE CITED}

Akatsuka, H., Kawai, E., Omori, K., and Shibatani, T. 1995. The three genes $\operatorname{lip} B$, lipC, and lipD involved in the extracellular secretion of the Serratia marcescens lipase which lacks an N-terminal signal peptide. J. Bacteriol. 177:6381-6389.

Andersen, C., Koronakis, E., Hughes, C., and Koronakis, V. 2002. An aspartate ring at the TolC tunnel entrance determines ion selectivity and 
presents a target for blocking by large cations. Mol. Microbiol. 44:11311139

Barabote, R. D., Johnson, O. L., Zetina, E., San Francisco, S. K., Fralick, J. A., and San Francisco, M. J. 2003. Erwinia chrysanthemi tolC is involved in resistance to antimicrobial plant chemicals and is essential for phytopathogenesis. J. Bacteriol. 185:5772-5778.

Basar, T., Havlicek, V., Bezouskova, S., Hackett, M., and Sebo, P. 2001. Acylation of lysine 983 is sufficient for toxin activity of Bordetella pertussis adenylate cyclase. Substitutions of alanine 140 modulate acylation site selectivity of the toxin acyltransferase CyaC. J. Biol. Chem. 276:348-354.

Becker, A., Kleickmann, A., Arnold, W., and Puhler, A. 1993. Analysis of the Rhizobium meliloti exoH/exoK/exoL fragment: ExoK shows homology to excreted endo-beta-1,3-1,4-glucanases and ExoH resembles membrane proteins. Mol. Gen. Genet. 238:145-154.

Becker, A., Ruberg, S., Kuster, H., Roxlau, A. A., Keller, M., Ivashina, T., Cheng, H. P., Walker, G. C., and Puhler, A. 1997. The 32-kilobase exp gene cluster of Rhizobium meliloti directing the biosynthesis of galactoglucan: Genetic organization and properties of the encoded gene products. J. Bacteriol. 179:1375-1384.

Beringer, J. E. 1974. R factor transfer in Rhizobium leguminosarum. J. Gen. Microbiol. 84:188-198.

Beutler, H. O. 1984. Lactose and D-galactose: UV method. Pages 104-112 in: Methods of Enzymatic Analysis. H. U. Bergemeyer, ed. Verlag Chemie, Weinheim, Germany.

Bina, J. E., and Mekalanos, J. J. 2001. Vibrio cholerae tolC is required for bile resistance and colonization. Infect. Immun. 69:4681-4685.

Bleuel, C., Grosse, C., Taudte, N., Scherer, J., Wesenberg, D., Krauss, G. J., Nies, D. H., and Grass, G. 2005. TolC is involved in enterobactin efflux across the outer membrane of Escherichia coli. J. Bacteriol. 187:6701-6707.

Bradford, M. M. 1976. A rapid and sensitive method for the quantitation of microgram quantities of protein utilizing the principle of protein-dye binding. Anal. Biochem. 72:248-254.

Bullock, W. C., Fernandz, J. M., and Short, J. M. 1987. XL1-Blue: A high efficiency plasmid transforming recA Escherichia coli strain with betagalactosidase selection. Biotechniques 5:376-379.

Cardenas, L., Dominguez, J., Santana, O., and Quinto, C. 1996. The role of the nodI and nodJ genes in the transport of Nod metabolites in Rhizobium etli. Gene 173:183-187.

Casse, F., Boucher, C., Hulliot, J. S., Michel, M. F., and Dénarié, J. 1979. Identification and characterization of large plasmids in Rhizobium meliloti using agarose gel electrophoresis. J. Bacteriol. 113:229-242.

Chaplin, M. F., and Kennedy, S. F. 1986. Carbohydrate Analysis: A Practical Approach. IRL Press, Washington, DC.

Cheng, H. P., and Walker, G. C. 1998. Succinoglycan is required for initiation and elongation of infection threads during nodulation of alfalfa by Rhizobium meliloti. J. Bacteriol. 180:5183-5191.

Delepelaire, P. 2004. Type I secretion in gram-negative bacteria. Biochim. Biophys. Acta 1694:149-161.

Delgado, M. A., Solbiati, J. O., Chiuchiolo, M. J., Farias, R. N., and Salomon, R. A. 1999. Escherichia coli outer membrane protein TolC is involved in production of the peptide antibiotic microcin J25. J. Bacteriol. 181:1968-1970.

Djordjevic, M. A., Schofield, P. R., and Rolfe, B. G. 1985. Tn5 mutagenesis of Rhizobium-trifolii host-specific nodulation genes result in mutants with altered host-range ability. Mol. Gen. Genet. 200:463-471.

Finan, T. M., Hartwieg, E., LeMieux, K., Bergman, K., Walker, G. C., and Signer, E. R. 1984. General transduction in Rhizobium meliloti. J. Bacteriol. 159:120-124

Finnie, C., Hartley, N. M., Findlay, K. C., and Downie, J. A. 1997. The Rhizobium leguminosarum prsDE genes are required for secretion of several proteins, some of which influence nodulation, symbiotic nitrogen fixation and exopolysaccharide modification. Mol. Microbiol. 25:135-146.

Fralick, J. A. 1996. Evidence that TolC is required for functioning of the Mar/AcrAB efflux pump of Escherichia coli. J. Bacteriol. 178:58035805

Gibson, K. E., Barnett, M. J., Toman, C. J., Long, S. R., and Walker, G. C. 2007. The symbiosis regulator CbrA modulates a complex regulatory network affecting the flagellar apparatus and cell envelope proteins. J. Bacteriol. 189:3591-3602.

Goebel, W., and Hedgpeth, J. 1982. Cloning and functional characterization of the plasmid-encoded hemolysin determinant of Escherichia coli. J. Bacteriol. 151:1290-1298.

Gonzalez, J. E., Semino, C. E., Wang, L. X., Castellano-Torres, L. E., and Walker, G. C. 1998. Biosynthetic control of molecular weight in the polymerization of the octasaccharide subunits of succinoglycan, a symbiotically important exopolysaccharide of Rhizobium meliloti. Proc. Natl. Acad. Sci. U.S.A. 95:13477-13482.
Hackett, J., and Reeves, P. 1983. Primary structure of the tolC gene that codes for an outer membrane protein of Escherichia coli K12. Nucleic Acids Res. 11:6487-6495.

Harlow, E., and Lane, D. 1988. Antibodies: A Laboratory Manual. Cold Spring Harbor Laboratory, Cold Spring Harbor, NY, U.S.A.

Hoang, H. H., Becker, A., and Gonzalez, J. E. 2004. The LuxR homolog ExpR, in combination with the Sin quorum sensing system, plays a central role in Sinorhizobium meliloti gene expression. J. Bacteriol. 186:5460-5472.

Kaufmann, E., Geisler, N., and Weber, K. 1984. SDS-PAGE strongly overestimates the molecular masses of the neurofilament proteins. FEBS (Fed. Eur. Biochem. Soc.) Lett. 170:81-84.

Keller, M., Roxlau, A., Weng, W.M., Schmidt, M., Quandt, J., Niehaus, K., Jording, D., Arnold, W., and Puhler, A. 1995. Molecular analysis of the Rhizobium meliloti mucR gene regulating the biosynthesis of the exopolysaccharides succinoglycan and galactoglucan. Mol. Plant-Microbe Interact. 8:267-277.

Kessler, C. 1992. Nonradioactive Labelling and Detection of Biomolecules. Springer, Berlin.

Koronakis, V. 2003. TolC-the bacterial exit duct for proteins and drugs. FEBS (Fed. Eur. Biochem. Soc.) Lett. 555:66-71.

Koronakis, V., Sharff, A., Koronakis, E., Luisi, B., and Hughes, C. 2000. Crystal structure of the bacterial membrane protein TolC central to multidrug efflux and protein export. Nature 405:914-919.

Kunst, A., Draeger, B., and Zoegenhorn, J. 1984. UV methods with hexokinase and glucose-6-phosphate dehydrogenase. Pages 163-172 in: Methods of Enzymatic Analysis. H. U. Bergemeyer, ed. Verlag Chemie, Weinheim.

Leigh, J. A., Signer, E. R., and Walker, G. C. 1985. Exopolysaccharidedeficient mutants of Rhizobium meliloti that form ineffective nodules. Proc. Natl. Acad. Sci. U.S.A. 82:6231-6235.

Letoffe, S., Delepelaire, P., and Wandersman, C. 1990. Protease secretion by Erwinia chrysanthemi: The specific secretion functions are analogous to those of Escherichia coli alpha-haemolysin. EMBO (Eur. Mol. Biol. Organ.) J. 9:1375-1382

Meade, H. M., Long, S. R., Ruvkun, G. B., Brown, S. E., and Ausubel, F. M. 1982. Physical and genetic characterization of symbiotic and auxotrophic mutants of Rhizobium meliloti induced by transposon Tn5 mutagenesis. J. Bacteriol. 149:114-122.

Moreira, L. M., Becker, J. D., Puhler, A., and Becker, A. 2000. The Sinorhizobium meliloti ExpE1 protein secreted by a type I secretion system involving ExpD1 and ExpD2 is required for biosynthesis or secretion of the exopolysaccharide galactoglucan. Microbiology 146:2237-2248.

Neidhardt, F. C., Bloch, P. L., and Smith, D. F. 1974. Culture medium for enterobacteria. J. Bacteriol. 119:736-747.

Nielsen, H., Engelbrecht, J., Brunak, S., and von Heijne, G. 1997. Identification of prokaryotic and eukaryotic signal peptides and prediction of their cleavage sites. Protein Eng. 10:1-6.

Nikaido, H. 2000. How do exported proteins and antibiotics bypass the periplasm in Gram-negative bacterial cells? Trends Microbiol. 8:481483.

Posadas, D. M., Martin, F. A., Sabio y Garcia, J. V., Spera, J. M., Delpino, M. V., Baldi, P., Campos, E., Cravero, S. L., and Zorreguieta, A. 2007. The TolC homologue of Brucella suis is involved in resistance to antimicrobial compounds and virulence. Infect. Immun. 75:379-389.

Quester, I., and Becker, A. 2004. Four promoters subject to regulation by ExoR and PhoB direct transcription of the Sinorhizobium meliloti exoYFQ operon involved in the biosynthesis of succinoglycan. J. Mol. Microbiol. Biotechnol. 7:115-132.

Reddy, J. D., Reddy, S. L., Hopkins, D. L., and Gabriel, D. W. 2007. TolC is required for pathogenicity of Xylella fastidiosa in Vitis vinifera grapevines. Mol. Plant-Microbe Interact. 20:403-410.

Reyes, F., Roldan, M. D., Klipp, W., Castillo, F., and Moreno-Vivian, C. 1996. Isolation of periplasmic nitrate reductase genes from Rhodobacter sphaeroides DSM 158: Structural and functional differences among prokaryotic nitrate reductases. Mol. Microbiol. 19:1307-1318.

Rivilla, R., Sutton, J. M., and Downie, J. A. 1995. Rhizobium leguminosarum NodT is related to a family of outer-membrane transport proteins that includes TolC, PrtF, CyaE and AprF. Gene 161:27-31.

Rolfe, B. G., Gresshoff, P. M., Shine, J., and Vincent, J. M. 1980. Interaction between a non-nodulating and an ineffective mutant of Rhizobium trifolli resulting in effective (nitrogen-fixing) nodulation. Appl. Environ. Microbiol. 39:449-452.

Ruberg, S., Puhler, A., and Becker, A. 1999. Biosynthesis of the exopolysaccharide galactoglucan in Sinorhizobium meliloti is subject to a complex control by the phosphate-dependent regulator PhoB and the proteins ExpG and MucR. Microbiology 145:603-611.

Sambrook, J., Fritsch, E. F., and Maniatis, T. 1989. Molecular Cloning: A Laboratory Manual. Cold Spring Harbor Laboratory, Cold Spring Harbor, NY, U.S.A. 
Scheu, A. K., Economou, A., Hong, G. F., Ghelani, S., Johnston, A. W., and Downie, J. A. 1992. Secretion of the Rhizobium leguminosarum nodulation protein NodO by haemolysin-type systems. Mol. Microbiol. 6:231-238.

Sharff, A., Fanutti, C., Shi, J., Calladine, C., and Luisi, B. 2001. The role of the TolC family in protein transport and multidrug efflux. From stereochemical certainty to mechanistic hypothesis. Eur. J. Biochem. 268:5011-5026.

Sharypova, L. A., Yurgel, S. N., Keller, M., Simarov, B. V., Puhler, A., and Becker, A. 1999. The eff-482 locus of Sinorhizobium meliloti CXM1105 that influences symbiotic effectiveness consists of three genes encoding an endoglycanase, a transcriptional regulator and an adenylate cyclase. Mol. Gen. Genet. 261:1032-1044.

Sharypova, L. A., Chataigne, G., Fraysse, N., Becker, A., and Poinsot, V. 2006. Overproduction and increased molecular weight account for the symbiotic activity of the rkpZ-modified $\mathrm{K}$ polysaccharide from $\mathrm{Si}$ norhizobium meliloti Rm1021. Glycobiology 16:1181-1193.

Simon, R., Priefer, U., and Puhler, A. 1983. A broad-host-range mobilization system for in vivo genetic engineering: Transposon mutagenesis in gram-negative bacteria. Biotechnology 1:784-791.

Spaink, H. P., Wijfjes, A. H., and Lugtenberg, B. J. 1995. Rhizobium NodI and NodJ proteins play a role in the efficiency of secretion of lipochitin oligosaccharides. J. Bacteriol. 177:6276-6281.
Stanley, P., Packman, L. C., Koronakis, V., and Hughes, C. 1994. Fatty acylation of two internal lysine residues required for the toxic activity of Escherichia coli hemolysin. Science 266:1992-1996.

Toporowski, M. C., Nomellini, J. F., Awram, P., and Smit, J. 2004. Two outer membrane proteins are required for maximal type I secretion of the Caulobacter crescentus S-layer protein. J. Bacteriol. 186:80008009

Towbin, H., Staehelin, T., and Gordon, J. 1979. Electrophoretic transfer of proteins from polyacrylamide gels to nitrocellulose sheets: Procedure and some applications. Proc. Natl. Acad. Sci. U.S.A. 76:43504354.

Watt, S. A., Wilke, A., Patschkowski, T., and Niehaus, K. 2005. Comprehensive analysis of the extracellular proteins from Xanthomonas campestris pv. campestris B100. Proteomics 5:153-167.

Whitfield, C. 2006. Biosynthesis and assembly of capsular polysaccharides in Escherichia coli. Annu. Rev. Biochem. 75:39-68.

York, G. M., and Walker, G. C. 1997. The Rhizobium meliloti exoK gene and prsD/prsE/exs $H$ genes are components of independent degradative pathways which contribute to production of low-molecular-weight succinoglycan. Mol. Microbiol. 25:117-134.

York, G. M., and Walker, G. C. 1998. The Rhizobium meliloti ExoK and ExsH glycanases specifically depolymerize nascent succinoglycan chains. Proc. Natl. Acad. Sci. U.S.A. 95:4912-4917. 